American Journal of Applied Sciences 7 (2): 241-247, 2010

ISSN 1546-9239

(c) 2010 Science Publications

\title{
Key Performance Indicators Supporting Decision-Making Affecting Malaysian Enterprise' Project Performance in China
}

\author{
${ }^{1}$ Abdullah Bin Ibrahim and ${ }^{1} \mathrm{Wu}$ Jing and ${ }^{2}$ Da Wenge \\ ${ }^{1}$ Faculty of Technology Management, \\ University of Malaysia Pahang, Kuantan 26300, Malaysia \\ ${ }^{2}$ Faculty of Mechanical and Electronic Engineering, \\ University of Malaysia Pahang, Kuantan, Malaysia
}

\begin{abstract}
Problem statement: Nowadays, Improving decision-making to define a group of strategic objectives and associated Performance Indicators (KPIs) are has become one of the critical issues for practices relating to scope management gaining competitive advantages. Approach: This study focus on validate KPI supporting decision-making for sustainability appraisal in projects management for Malaysian Architectural, Engineering and Construction (AEC) enterprises in China. Results: First, it need to identify key issues related to sustainable intelligent buildings (AEC factors) and determines the performance level of their projects in China. Second, test critically decisionmakers perceptions and values of selected KPIs intelligent buildings to supporting decision-making processes. Third to develop a conceptual model for the selection of the appropriate KPIs for measuring the level of sustainability for sustainable intelligent buildings, this provides information as to whether practices could be adopted by Malaysian AEC enterprises in China to achieve objectives. Conclusion: This study established KPIs-SDM practices that are significantly correlated with the projects handled by Malaysian enterprises in China. It investigated and compare 19 KPIsSDM relational factors for Malaysian AEC project adopted in China.
\end{abstract}

Key words: The result shows that cross-enterprises decision, it is not only can validate crucial KPIs but also can help enterprises achieve better project performance in China

\section{INTRODUCTION}

As for the growing of economy in this century, China's architectural, engineering and construction industry currently ranks amongst the largest in the world. The decision-making based on KPI may be an effective one because it is emphasized as a central scheme in project performance (Zhi, 1995).

In this sense many researchers have recently pointed out the KPI level as a source of additional meaningful information for enterprises project management. Notwithstanding the favorable conditions, problems of cost outrun and schedule delay are frequently reported in China (Wang and Jiang, 1994). This focus is chosen because international construction involves all the uncertainties common in domestic projects as well as risks specific to international transactions (Han et al., 2005). Besides the typical risks of a domestic project, international projects have a complex and subtle web of political, economic and cultural risks (Han and Diekmann, 2001). Other risks associated with international construction include: Host government-related risks, shortage of financial resources and inflation, currency and interest rate fluctuations (Zhi, 1995; Gunhan and Arditi, 2005a). Analysts define KPI that the enterprises think are the most appropriate for reflecting project performance. It is intended that the process of obtaining the project from these decision will be adequate in terms of KPI. Contracting outside one's home country is usually considered a high risk business, mostly because of the lack of adequate overseas environmental information and overseas construction experience (Cross and Lynch, 1988). Researchers have developed different project management for managing organizations such as (Atkinson et al., 1997; Alfaro Saiz et al., 2007). All of them coincide in defining objectives and some sort of indicators to monitor the accomplishment of such objectives.

This study present validate Key Performance Indicators (KPIs) to Supporting Decision-Making (SDM) for sustainability appraisal in projects

Corresponding Author: Abdullah Bin Ibrahim, Faculty of Technology Management, University of Malaysia Pahang, Kuantan 26300, Malaysia 
management. Defines some objectives derived from decision-making and one associated set of key performance indicators. A project performance management system includes many management processes, such as defining targets, planning, communication, monitoring, reporting and feedback. These processes have been embedded in decisionmaking system solutions. KPI supporting decisionmaking is critical for companies to improve project performance effectiveness and efficiency. In addition, these system solutions measure and KPIs which are crucial for optimizing project performance.

The rest of the research is organized as follows: Part two reviews current research in KPI project management science and find out the existing gaps. Materials and methods proposed framework for analysis of projects management, and a systematic approach to decision based on KPIs. Results discuss an illustrative application of this methodology in projects management of AEC industry. Finally, conclusions and recommendations for the KPI of decision-making and projects management while Malaysian enterprises enter to China in conclusion.

Related work: Several studies have been conducted on how project success can be measured (Konchar and Sanvido, 1998; Molenaar and Songer, 1998). Supporting decision-making to Improving project management performance is a continuous process that requires both an analytical performance measurement system and a mechanism to initiate steps for realizing KPI goals. Herein we call the mechanism to achieve KPI goals as "KPI accomplishment”, which connects planning and execution and builds steps for realization of performance goals into project work. To measure performance, there are a set of variables that capture the impact of actual working of project management on revenues and costs of the whole system (Ramdas and Spekman, 2000).

At the broader international research level, the areas discussed in literature include group decisionmaking (Seager and Theis, 2004; Seager, 2004), multiattribute decision analysis (Rogers et al., 2004; Annex and Focht, 2002). Others focused on multi-criteria decision analysis applications in designing for environment and other forms of selection appraisal problems (Brins and Vinke, 2002; Hokkanen and Salminen, 1997; Salminen et al., 1998).

Pinto and Slevin (1988) found ten critical success factors that are significantly related to project success using regression analysis. These factors are project mission, top management support, project schedule and plans, client consultation, personnel, technical expertise, client acceptance, monitoring and feedback, communication and troubleshooting. Four external factors are found to significantly affect project success characteristics of the team leader, power and politics, environmental events and urgency of the project. Sanvido et al. (1992) examined the contribution of different factors to project success and found project team experience, contracts, resources and information available as important factors.

Profit performance in international construction projects may be predicted using a regression model developed by Han et al. (2007). These performance measures were systematically analyzed and six measures were selected after the pilot survey. These six success measures are budget performance, schedule performance, quality performance, owner satisfaction, profitability, public satisfaction.

Chua et al. (1997) identified eight key management factors that affect budget performance. They are organizational levels between project manager and crafts men, project manager experience, level of design completion at the start of the project, constructability programme, project team workmanship rate, frequency of control meetings, frequency of budget updates and control system budget. Using the same set of data, five key factors affecting schedule performance, i.e., frequency of meetings, amount of time that project managers devote to the project, project manager's experience, monetary incentives to designers and implementation of constructability programme, were found (Kog et al., 1999).

Market entry modes have been previously investigated (Gunhan and Arditi, 2005b; Ling et al., 2005a) and so have organizational level management strategies (Gala and Luo, 2004; Ling et al., 2005a; 2005b; 2006; Luo, 2001). Jaselskis and Ashley (1991) identified determinants for budget performance using logistic regression. They found that the most important variable is 'implementation of constructability programme'.

Projects that are located outside of one's home country (international projects) are more difficult to manage than domestic projects because of multiple ownership, elaborate financial provisions (Gunhan and Arditi, 2005a) and higher uncertainty, complexity and cost.

A brief literature review revealed that while many studies on project success factors have been done, these are primarily focused on indigenous enterprises working in their home countries and the project decision without KPI supporting. The influence of foreign enterprises' project performance on the success of an international project remains unclear. There is a 
gap in knowledge relating to KPI determinants that affect different aspects of project performance.

This study therefore aimed to fill the gap by exploring the how KPI support decision-making to project performance that Malaysia AEC enterprises adopt to achieve project success in China. This framework is anchored in validating the KPI required for decision-making at the project management. These would facilitate the formulation of underpinning mathematical/decision models and assessment methods for quantitative analysis and decision-support in project management.

\section{MATERIALS AND METHODS}

Proposed method: Figure 1 illustrates the idea of introducing an activity of identifying relationships between KPIs of a SDM and their posterior upstream projection within a SDM.

From Fig. 1, it is possible to conclude that:

- To be a standard methodology to be applied to any SDM that clearly establishes traceability between their objectives and associated KPIs

- There are a multitude of methods and frameworks applied to both performance measurement and management, but almost all make subjective considerations at any step. The few ones whose research aim is close to the present work stop when they find KPIs of decision-making. Besides, the method used for finding these factors affecting project performance is either inappropriate or has got inherent limitations that makes impossible the finding of all the factors

- Though not applied to this ambit extensively, the multivariate techniques are the most appropriate. Then, down to data characteristics, either the principal component analysis or the structural equation model for identifying KPIs of decisionmaking

- To resume, there is not any project performance framework that explicatively incorporates any mechanism for identifying, quantifying and projecting upstream the existing relationships between KPIs of decision-making and project performance

- To provide the necessary mechanisms for projecting these KPI cause-effect relationships upstream in the PMS towards the objectives ambit

Finally, at the performance measurement context, there are some frameworks that aim to identify any sort of relationship between performance elements.
Thus to apply a correlation analysis to quantify relationships between pairs of KPIs defined within the design of a SDM. This work uses the quantified relationships for assessing one model designed to react to external changes that might affect one organization instead of projecting them upstream in the SDM.

KPI-SDM has got the following Five phases:

Phase 1: To develop and analysis of the SDM model.

Phase 2: Initial data treatment.

Phase 3: Identification of KPI parameter relationships.

Phase 4: Effect of KPIs parameter on SDM

Phase 5: Presentation and analysis of results.

Each phase has different main activities to be carried out and they are all described and justified next:

Phase 1: To develop and analysis of the SDM model: In the first step the enterprise develop and analysis a SDM. In order to apply this proposal, it must clearly establish the links between the objectives and the associated performance indicators. Once the SDM has been developed, it has to be analyzed, then decisionmakers should check out the consistency of the different objectives for each perspective and associated KPIs in order to detect possible failures and correct them.

Phase 2: Initial data treatment: In this phase the data collected by the KPIs-SDM is brought in order to begin its analysis. For analysis, all the data coming from the KPIs-SDM in the enterprise. This phase implies the application of centering operations, which will allocate the same degree of importance to each variable. Since the KPIs are very heterogeneous with regard to their measurement units (time, \%) the centering technique to be applied in this proposal that technique combines centering and standardization techniques as shown in Fig. 2.

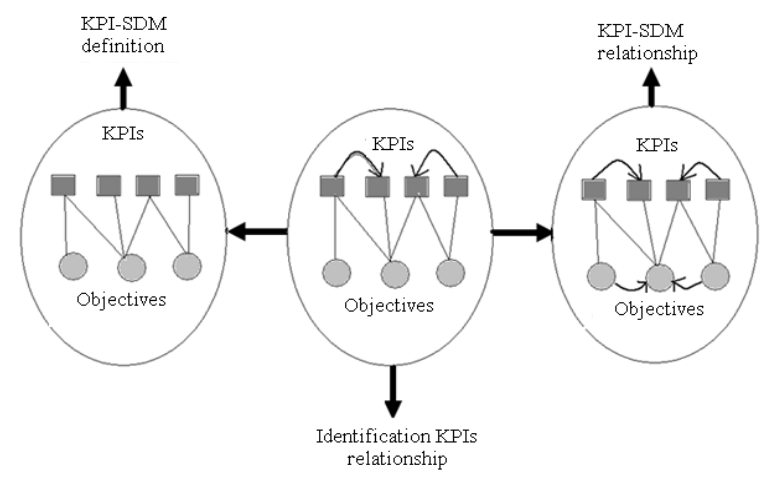

Fig. 1: Identification of KPIs-SDM relationships 
Am. J. Applied Sci., 7 (2): 241-247, 2010

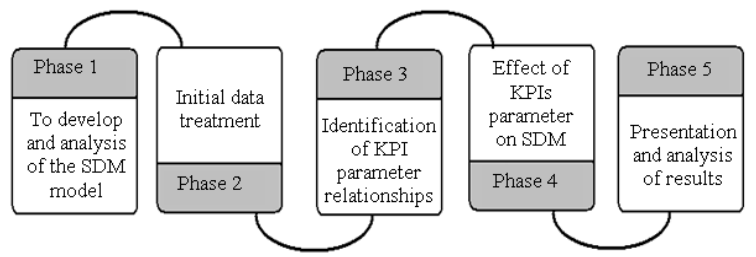

Fig. 2: KPIs-SDM phases

Phase 3: Identification of KPI parameter relationships: This phase identifies and quantifies relationships between KPIs by applying adequate techniques to the initial data. In addition, KPIs-SDM helps to establish decision models through a process that contains both qualitative and quantitative components. Identify 'priority level' and the value for each indicator, it can be translated into a numerical score. Moreover, the importance of this indicator is further modified by a weighting to represent its priority within the criteria group. To summarize, the value of the multipliers are based on the importance of each criterion which is weighted according to its importance in each case.

Phase 4: Effect of KPIs parameter on SDM: All KPIs strongly and significantly correlate with each other, they bear strong relationships. Strong correlations between various KPIs may imply that they are similar to each other (or overlap each other) and hence can be reduced by using factor analysis. However, it should noted that some of these KPIs are quantitative where as others are qualitative in nature. Combining them through factor analysis would not serve any purpose except for effection.

To enable the enterprises to make effective decisions on complex issues by helping to order the factors involved in their decision-making processes. The SDM approach can help to improve the effect of decision-making process and has been applied to the enterprises in the last year.

KPIs-SDM helps enterprises to establish decision models through a process that contains both qualitative and quantitative components. Qualitatively, it can building decision problem from the overall goal into a set of manageable categories and indicators. Quantitatively, it uses pair-wise comparison to assign weights to the elements at the indicator levels.

Phase 5: Presentation and analysis of results: Findings in this study show that there is significant concern about efficiency and quality. These results show that the AEC decision-maker are starting to think beyond the traditional measures of project performance.
This research suggests that enterprises should be considered as the new measure of performance on AEC projects in China. There are four levels at which KPIs should be looked at. Issues related to cost, time, risk quality and human resource are at the core of KPIsSDM.

KPIs-SDM are presented within the perspective they belong to, which makes easier their posterior projection upstream and also gives a more complete global picture of the different level. The analysts can study the different cause-effect indicators and confirm expected indicators, which have been demonstrated with this study and also about non-expected indicators that may arise. At this time, redundancy between KPIsSDM might be identified as well as to clearly identify what the main KPIs-SDM causes are. Once the KPIsSDM has been constructed, it is time to project the identified cause-effect relationships upstream in the project management.

More over the data gathered by the KPIs will come defined in the KPIs-SDM, according to their associated objectives and it will be related to any process that the enterprise is interesting in monitoring, controlling and measuring, as derived from its strategy.

\section{RESULTS}

KPIs-SDM has been applied to one enterprise with more than 185 people that construction enterprise in the China. This enterprise had already implemented a KPIsSDM in previous years and in this case the application of KPIs-SDM took around 3 months, obtaining very interesting results, which are presented below:

Currently, there are in total 19 defined KPIs, within six criteria. The criteria are cost, time, risk, quality, human resource and integration as shown in Table 1. The KPIs are measured across different stages of a construction project. The stages were identified to provide definition of the data required to be used in the calculation of the KPIs. This was established to enable benchmarking to take place.

The enterprise uses balanced scorecard to measure the KPIs-SDM, There are 19 areas where indicators are developed.

Country legal and political risk is the big issue that foreign enterprises always thinking about. The political evolutionary process has resulted in the democratic government introducing affirmative actions. Such risk include social-policy oriented issues related to public health and safety, land ownership, long-term occupational health (e.g., respiratory duct disease and permanent deafness), regulation relate to accidents, injuries and fatalities at construction sites and associated compensations. 
Am. J. Applied Sci., 7 (2): 241-247, 2010

Table1: Criteria KPIs-SDM Factors

\begin{tabular}{|c|c|c|c|}
\hline Rank & Item & Indicator & $\begin{array}{l}\text { Practice } \\
(\%)\end{array}$ \\
\hline \multirow[t]{2}{*}{1} & Cost & Use high quality cost control techniques & 28 \\
\hline & & Profitability & 33 \\
\hline \multirow[t]{3}{*}{2} & Time & Performance time control & 25 \\
\hline & & $\begin{array}{l}\text { Plan high quality schedule and update } \\
\text { it frequently }\end{array}$ & 36 \\
\hline & & Procedure for partner selection & 13 \\
\hline \multirow[t]{3}{*}{3} & Risk & Control country and legal risks & 44 \\
\hline & & Control political risk & 39 \\
\hline & & Control language barrier risk effectively & 15 \\
\hline \multirow[t]{5}{*}{4} & Quality & Quality of financial management & 26 \\
\hline & & $\begin{array}{l}\text { Give high quality responses towards } \\
\text { perceived variations }\end{array}$ & 32 \\
\hline & & Manage health and safety in the project & 30 \\
\hline & & Prepare high quality contract document & 16 \\
\hline & & Quality of communication system & 6 \\
\hline \multirow[t]{2}{*}{5} & HR & $\begin{array}{l}\text { Employ fewer locals (Chinese) as } \\
\text { professional staff and workmen }\end{array}$ & 10 \\
\hline & & $\begin{array}{l}\text { Provide adequate workmen to execute } \\
\text { the work }\end{array}$ & 7 \\
\hline \multirow[t]{3}{*}{6} & Integration & $\begin{array}{l}\text { Manage public image and pubic } \\
\text { relations }\end{array}$ & 5 \\
\hline & & Owner satisfaction & 11 \\
\hline & & Public satisfaction & 4 \\
\hline
\end{tabular}

There is significant correlation between foreign enterprises' ability to control both cost and quality. The KPI-SDM practices adopted in international (China) construction are similar to those adopted in domestic construction for improving cost performance.

\section{DISCUSSION}

This study shows that Quality of schedule control is significantly correlated with cost management for international AEC. This is similar to domestic construction practice, whereby relationships of different parties and work sequences should be viewed as an entirety as the impact of one event or decision could affect overall project performance.

This may be explained by the fact that traditional bid-design-build method is common in the Chinese construction industry. It was adopted in most projects in this study. Without effective management of interaction between design and construction teams, high quality responses towards perceived variations would intensify the fragmentation of design and construction rather than save money and time, improve quality and achieve harmonious relationships.

The high rankings indicate very high levels of awareness on health and safety-related matters in construction and the wider society. Quality performance is not only limited to the quality of health, safety and environmental protection but also includes high quality contract document. Thus, during project delivery, the ability to deal with high quality contract document, control environmental disturbances and site safety effectively would lead to higher self and public satisfaction for the project.

Table 1 shows that quality performance is the bedrock upon which other performance areas can be improved. Enterprises that are able to achieve high quality output appear to also achieve high profitability, high level of owner satisfaction and high public satisfaction.

Projects in China may face communication and multi-national coordination. The implication is that foreign enterprises that operate in China need to manage this additional dimension which may not be needed when operating in their home countries. There is significant correlation with foreign enterprises' ability to control language barrier risk. Language barrier between project participants may result in communication breakdown, which may lead to greater amount of reworks and cause schedule and cost overrun. It is recommended that differences in language may be overcome by getting foreigners to learn Chinese language; or engaging staff who already know Chinese language.

Construction processes in China depend heavily on manual labor and even though the labor is cheap, they are unskilled. It is recommended that these workers be sent for training and re-training, so as to increase their productivity.

The result shows positive correlation between public image/relations and Public and owner satisfaction. If public relation is not well managed, complaints from the public may require counteractive measures to be taken which may lead to cost increase, thereby reducing profit level.

\section{CONCLUSION}

This study established KPIs-SDM practices that are significantly correlated with the projects handled by Malaysian enterprises in China. It investigated and compare 19 KPIs-SDM relational factors for Malaysian AEC project adopted in China. The data were collected from experienced Malaysian construction enterprise who had been personally involved in undertaking projects in China. Five critical factors are uncovered to affect the project performance metrics. It is recommended that Malaysian enterprises involved in the Chinese AEC industry concentrate on the KPIs-SDM factors having entered the optimum models constructed. In addition, foreign enterprises that have entered or are going to enter the Chinese construction industry may learn how to build cooperative and harmonious relationships 
with Chinese partners and finally achieve satisfactory project performance by paying sufficient attention to the aforementioned factors. Finally, the analysis revealed that projects performance had achieved success, the most affecting factors are cost, time, risk, quality, human resource.

\section{REFERENCES}

Alfaro Saiz, J.J., A. O. Bas and R.R. Rodriguez, 2007. Performance measurement system for enterprise networks. Int. J. Productive Perform. Manage., 56: 305-334. DOI: 10.1108/17410400710745324

Annex, R.P. and W. Focht, 2002. Public participation in life cycle assessment and risk assessment: A shared need. Risk Anal., 22: 861-877.

Atkinson, A.A., J.H. Watherhouse and R.B. Wells, 1997. A stakeholder approach to strategic performance measurement. Sloan Manage. Rev., 38: 25-37.

Brins, J.P. and P. Vinke, 2002. Note- A: A preference ranking organization method. Manage. Sci., 31: 647-656.

Chua, D.K.H., Y.C. Kog, P.K. Loh and E.J. Jaselskis, 1997. Model for construction budget performanceneural network approach. J. Constr. Eng. Manage., 123: 214-222. DOI.10.1061/(ASCE)07339364(1997)123:3(214)

Cross, K.F. and R.L. Lynch, 1988. The "SMART" way to sustain and define success. Nal. Prod. Rev., 8: 23-33. DOI: 10.1002/npr.4040080105

Gale, A. and J. Luo, 2004. Factors affecting construction joint ventures in China. Int. J. Project Manage., 22: 33-42.

Gunhan, S. and D. Arditi, 2005a. Factors affecting international construction. J. Constr. Eng. Manage., 131: 273-282. DOI: 10.1061/(ASCE)07339364(2005)131:3(273)

Gunhan, S. and D. Arditi, 2005b. International expansion decision for construction companies. J. Constr. Eng. Manage., 131: 928-937. DOI: 10.1061/(ASCE)0733-9364(2005)131:8(928)

Han, S.H. and J.E. Diekmann, 2001. Approaches for making risk-based go/no-go decision for international projects. J. Constr. Eng. Manage., 127: 300-308. DOI: 10.1061/(ASCE)07339364(2001)127:4(300)

Han, S.H., D.Y. Kim and H. Kim, 2007. Predicting profit performance for selecting candidate international construction projects. J. Constr. Eng. Manage., 133: 425-436. DOI: 10.1061/(ASCE)0733-9364(2007)133:6(425)

Han, S.H., J.E. Diekmann and J.H. Ock, 2005 Contractor's risk attitudes in the selection of international construction projects. J. Constr. Eng. Manage., 131: 283-292. DOI: 10.1061/(ASCE)0733-9364(2005)131:3(283)
Hokkanen, J. and P. Salminen, 1997. Locating a waste treatment facility by multi-criteria analysis. J. Multicriter. Dec. Anal., 6: 175-184. DOI: 10.1002/(SICI)1099-1360(199705)6:3<175::AIDMCDA150>3.0.CO;2-\#

Jaselskis, E.J. and D.B. Ashley, 1991. Optimal allocation of project management resources for achieving success. J. Constr. Eng. Manage., 117: 321-340. DOI: 10.1061/(ASCE)07339364(1991)117:2(321)

Kog, Y.C., D.K.H. Chua, P.K. Loh and E.J. Jaselskis, 1999. Key determinants for construction schedule performance. Int. J. Proj. Manage., 17: 351-359. DOI: 10.1016/S0263-7863(98)00058-1

Konchar, M. and V. Sanvido, 1998. Comparison of U.S. project delivery systems. J. Constr. Eng. Manage., 124: 435-444.

Ling, F.Y.Y., C.W. Ibbs and J.C. Cuervo, 2005a. Entry and business strategies used by international AEC firms in China. Constr. Manage. Econ., 23: 509-520. DOI: 10.1080/01446190500040141

Ling, F.Y.Y., C.W. Ibbs and M.M. Kumaraswamy, 2005b. Enablers that help foreign architectural, engineering and construction firms win construction contracts in China. J. Manage. Eng., 21: 63-69. DOI: 10.1061/(ASCE)0742-597X(2005)

Ling, F.Y.Y., C.W. Ibbs and W.Y. Hoo, 2006. Determinants of international architectural, engineering and construction firms' project success in China. J. Constr. Eng. Manage., 132: 206-214. DOI: 10.1061/(ASCE)0733-9364(2006)132:2(206)

Luo, J., 2001. Assessing management and performance of Sino-foreign construction joint ventures. Constr. Manage. Econ., 19: 109-117.

Molenaar, K.R. and A.D. Songer, 1998. Model for public sector design-build project selection. J. Constr. Eng. Manage., 124: 467-479. DOI: 10.1061/(ASCE)0733-9364(1998)124:6(467)

Pinto, J.K. and D.P. Slevin, 1988. Critical success factors across the project life cycle. Proj. Manage. J., 19: 67-75.

Ramdas, K. and R.E. Spekman, 2000. Chain or shackles: Understanding what drives supply-chain performance. Interfaces, 30: 3-21. DOI: 10.2307/25062616

Rogers, S.H., T.P. Seager and K.H. Gardner, 2004. Combining Expert Judgment and Stakeholder Values with PROMETHEE: A Case Study in Contaminated Sediments Management. In: Comparative Risk and Environmental DecisionMaking, Linkov, I. and A.B. Ramadan (Eds.). Kluwer Academic Press, Boston, USA., pp: 305-322. 
Salminen, P., J. Hokkanen and R. Lahdelma, 1998. Comparing multicriteria methods in the context of environmental problems. Eur. J. Operat. Res., 104: 485-96. DOI: 10.1016/S0377-2217(96)00370-0

Sanvido, V., F. Grobler, K. Parfitt, M. Guvenis and M. Coyle, 1992. Critical success factors for construction projects. J. Constr. Eng. Manage., 118: 94-111. DOI: 10.1061/(ASCE)07339364(1992)118:1(94)

Seager, T.P. and T.L. Theis, 2004. A taxonomy of metrics for testing the industrial ecology hypotheses and application to design of freezing insulation. J. Cleaner Prod., 12: 865-875.
Seager, T.P., 2004. Understanding Industrial and the Multiple Dimensions of Sustainability. In: Strategic Environmental Management for Engineers, O'Briene, A., A. Gere and R. Bellandi (Eds.). Wiley, New York, USA., ISBN: 978-0-47109221-6, pp: 17-70.

Wang, B. and H. Jiang, 1994. The review of tendering practice. J. Constr. Market Tender., 3: 31-34.

Zhi, H., 1995. Risk management for overseas construction projects. Int. J. Proj. Manage., 13: 231-237. DOI: 10.1016/0263-7863(95)00015-I 